\title{
Why Do Some Lao Mothers Have Good Practices During Pregnancy? A Qualitative Positive Deviance Study
}

\author{
Sysavanh Phommachanh ${ }^{1 * \mathbb{1}}$, Dirk R. Essink ${ }^{2}$, E. Pamela Wright ${ }^{3}$, Mayfong Mayxay ${ }^{1,4,5}$, Jacqueline E.W. \\ Broerse $^{2}$
}

\begin{abstract}
Objectives: Optimal antenatal care (ANC) visits help improve health outcomes and decrease perinatal mortality but they are often not optimal in low and middle-income countries (e.g., few mothers attend the recommended four or more ANC visits). The aim of this study was to identify determinants that influenced mothers who did make sufficient visits for ANC in rural Lao in order to inform the design of more effective interventions to change the behavior of mothers who do not make such visits.

Materials and Methods: A qualitative study was conducted using semi-structured interviews with mothers who made four or more ANC visits during their last pregnancy in rural Lao. Manual analysis was used for open and thematic coding of the interview data.

Results: All mothers reported taking special care of themselves during pregnancy. They perceived the clear benefits of ANC visits regarding reassuring them of their health and reducing the risk of negative events. Family members, particularly husbands, played a key role in making decisions to seek more ANC when they were aware of its benefits. In addition, friends and neighbors were an important source of information for mothers. The quality of ANC provision and the provision of incentives such as an information booklet, along with soap and mosquito net were directly influencing factors in increasing ANC visits.

Conclusions: In general, feeling a need for taking special care during pregnancy was a common factor among pregnant women who did use ANC in rural Laos. Accordingly, improving the quality of ANC and increasing appreciation in communities regarding the need for good ANC are strongly recommended to increase attendance by all mothers.

Keywords: Positive deviance, Lao women, ANC visits, Influencing factors
\end{abstract}

\section{Introduction}

Antenatal care (ANC) is a core healthcare function, including health promotion, screening, diagnosis, and disease prevention, ${ }^{1}$ which women receive throughout their pregnancy and the postpartum period. ${ }^{2}$ Optimal ANC contacts are recommended by the World Health Organization (WHO) to reduce perinatal mortality while improving women's experiences of care and health outcomes. ${ }^{3,4}$. However, in most low- and middle-income countries (LMICs), only a minority of mothers attends the recommended number of at least four ANC visits. ${ }^{5-8}$ Accordingly, this study investigated the factors that influenced the decision making of mothers who did attend four or more ANC visits and followed the advice of health providers.

Research in other countries has identified various factors that contributed to positive practices among women who made four or more ANC visits during their pregnancy. For example, women with a history of stillbirth, a highrisk medical or obstetric history, or those who are in a first pregnancy may be more likely to seek ANC. ${ }^{5,10}$ Other factors included an urban residence, women's education, family wealth, and few household occupants. ${ }^{6,11,12}$ Receiving maternal and child health $(\mathrm{MCH})$ information from a lady health worker, a nurse/midwife, the motherin-law or other relatives/friends, or mass media has been strongly associated with at least four or more ANC visits. ${ }^{7,11}$ In addition, the quality of the provided ANC, the accessibility of the service, and the behavior of health care providers are significantly associated with women making four or more ANC visits. ${ }^{3,7,10}$

A recent study demonstrated that $39.3 \%$ of Lao mothers had made four or more ANC visits, and this behavior was strongly associated with maternal and child health literacy (MCHL) (submitted paper, 2019). Other studies showed that education level, household income, time constraint, costs, and transportation were likely to be associated with ANC utilization. ${ }^{13-16}$ Previous studies demonstrated that knowledge, attitude, and the perception of ANC usefulness were also strongly associated with making sufficient ANC visits. ${ }^{15,16}$ However, these findings were based on quantitative data, along with one qualitative 
Key messages

- Gaining insight into the choices and motivations of positive deviant mothers in relation to ANC helps in selecting and designing effective interventions.

- Positive deviant mothers are possibly good role models in their communities to strengthen the needs of optimal ANC utilization.

study that mainly explored factors influencing mothers who made no ANC visits.

The primary objective of this study was to gain insights into the choices and motivations of mothers with positive practices in relation to optimal ANC visits, who were living in similar conditions to a majority of women who did not. The results could support potential interventions to increase the number of women using ANC in these areas.

\section{Materials and Methods}

Study Design

This qualitative study was carried out from May to June 2019, comprising semi-structured interviews with mothers who had made at least four ANC visits residing in a rural area of Attapeu Province. The study was inspired by the concept of "positive deviance". In a context where the majority of mothers did not seek ANC in the recommended way, we investigated what motivated or informed the women who took action in this regard. In Laos, where the behavior of attending ANC is still uncommon, these women can be considered as deviants in a positive way. The location was selected because it was the site of an MCHL study done in 2018, which identified potential participants for the current study.

\section{Site Selection and Recruitment}

This study was part of a larger intervention study in four selected districts (two urban and two rural villages for each district) of two provinces (Attapeu and Salavan). Attapeu province was selected using a simple random sampling method. Further, two villages in a rural area were purposively selected as the study site. The selection criterion was the availability of mothers who had made the recommended four or more ANC visits living in a specific rural area, identified by the baseline study of the larger project. In that study, 151 (39.3\%) out of 384 interviewed mothers had made the required number of ANC visits, of whom 68 lived in the rural areas of the two provinces. The researchers planned to interview all 22 eligible women in the two rural villages in Attapeu province, but only 19 cases were available at the time planned for the interviews. Two cases left the village and one case died at that time interval. To recruit respondents, first, the researchers contacted a household member at the address provided during the MCHL study. Local authorities assisted in distributing an official letter to invite eligible participants a few days before the interview. None of the invited women declined to be interviewed.

Research Instrument

In this study, an interview guide was used based on a model combining the socio-ecological ${ }^{22}$ and the health belief models in order to identify the determinants of the positive behavior. ${ }^{18,20,21}$ Both models offer concepts that can help understand factors influencing women to perform the positive behavior. ${ }^{17-21}$ The socio-ecological model guides the analysis of factors at different levels including individual, interpersonal, organizational, community and policy levels (Figure 1). At the individual level, several issues were analyzed, including the socio-demographic characteristics of mothers, how they perceived the ANC services, and what motivated them to attend ANC. At the interpersonal level, the researchers focused on family members, friends, and neighbors who provided support to mothers to visit ANC. The organization level refers to health facilities where pregnant women experienced ANC services provided by health workers and public transportation. In addition, the community level includes factors related to community support for mothers for using ANC services. Finally, the policy level refers to factors that are related to national $\mathrm{MCH}$ strategies in Laos.

\section{Semi-structured Interviews}

The interviews were conducted in the homes of the participating mothers, where they would feel comfortable and are assured of their privacy. The interviewers included one Lao academic researcher (SP) and two local assistants. The local interviewers attended a three-day training course prior to data collection. Further, interview guides contained closed questions on socioeconomic characteristics and open questions were about mothers' motivation and factors that influenced their positive behavior and reasons in this respect. We also asked them about their thoughts on what other women did and why. The guides were piloted in a community far from the study site and they were finalized accordingly. The mothers were interviewed in the Lao language for approximately 60 minutes, and all interviews were recorded. Notes were made while conducting the interviews in order to combine with the recorded data later.

\section{Data Analysis}

The recordings and interview notes were used to generate verbatim transcripts for data analysis, which were analyzed manually. The research team read the transcripts several times and discussed the open coding process together to reach a consensus on the code tree. The data were then translated into English. According to the socio-ecological model (Figure 1), the qualitative data were classified into individual, interpersonal, organization/health facilities, and community levels to make inferences. The findings included direct quotes from participants, which were 


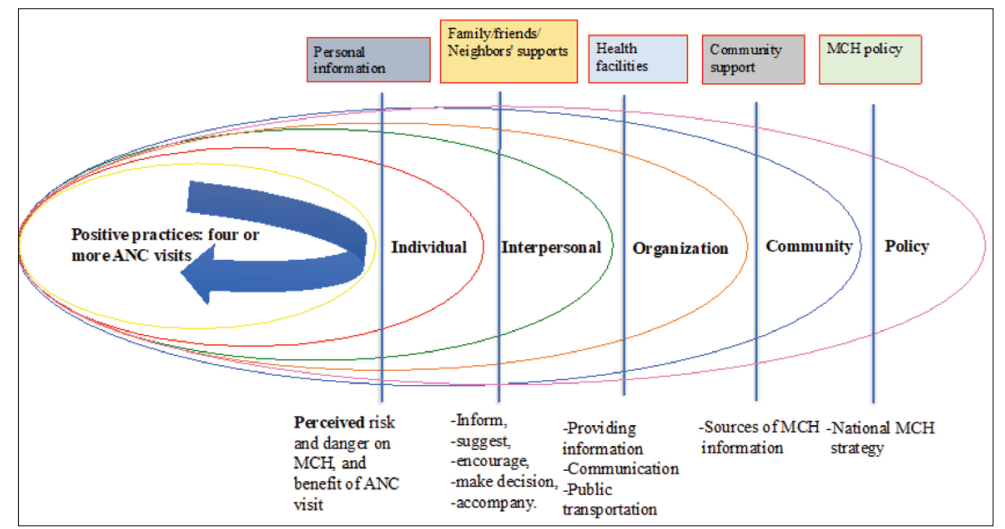

Figure 1. Integration of Socio-ecological Model for Positive Deviance Mothers.

translated into English and discussed with all researchers and supervisors to obtain consensus after analyzing the data.

\section{Results}

Our results provided information about what motivated and enabled mothers to perform their positive behaviors at individual, interpersonal, organization, and community levels (Figure 2) although the responses did not include factors that were directly related to the policy level. The mothers also reflected upon why others are not capable of performing these behaviors (Table 1).

Determinants of Positive ANC Practices of Lao Mothers: Reflections on Negative Practices

Individual Level

Three motivations to access ANC were identified on an individual level, including the belief or attitude toward 'special care' during pregnancy, the benefit of ANC for $\mathrm{MCH}$ as part of 'special care', and a fear of risk-taking.
When referring to good practices during pregnancy for which mothers often used the term 'special care' -, they included practices related to food consumption, physical activities, and health-seeking behaviors. Most mothers mentioned that eating enough and eating a good variety of food during pregnancy are very important for $\mathrm{MCH}$, which was the doctors' advice from "modern" health care. Some mothers mentioned that they drank milk and coconut water to benefit their baby while they avoided alcohol and smoking.

"I bought formula milk to drink, took vitamins, and ate all kinds of foods that are good for my health and my baby, especially eating meat, fish, chicken, vegetables, and fruit, as my doctor gave a piece of advice. I did not practice any food taboos but I did avoid drinking alcohol." (Participant No. 1)

Physical activity was also recommended by these mothers as part of their special care during pregnancy although most of them avoided very hard work and took more rest than usual, and some did exercises to ease childbirth.

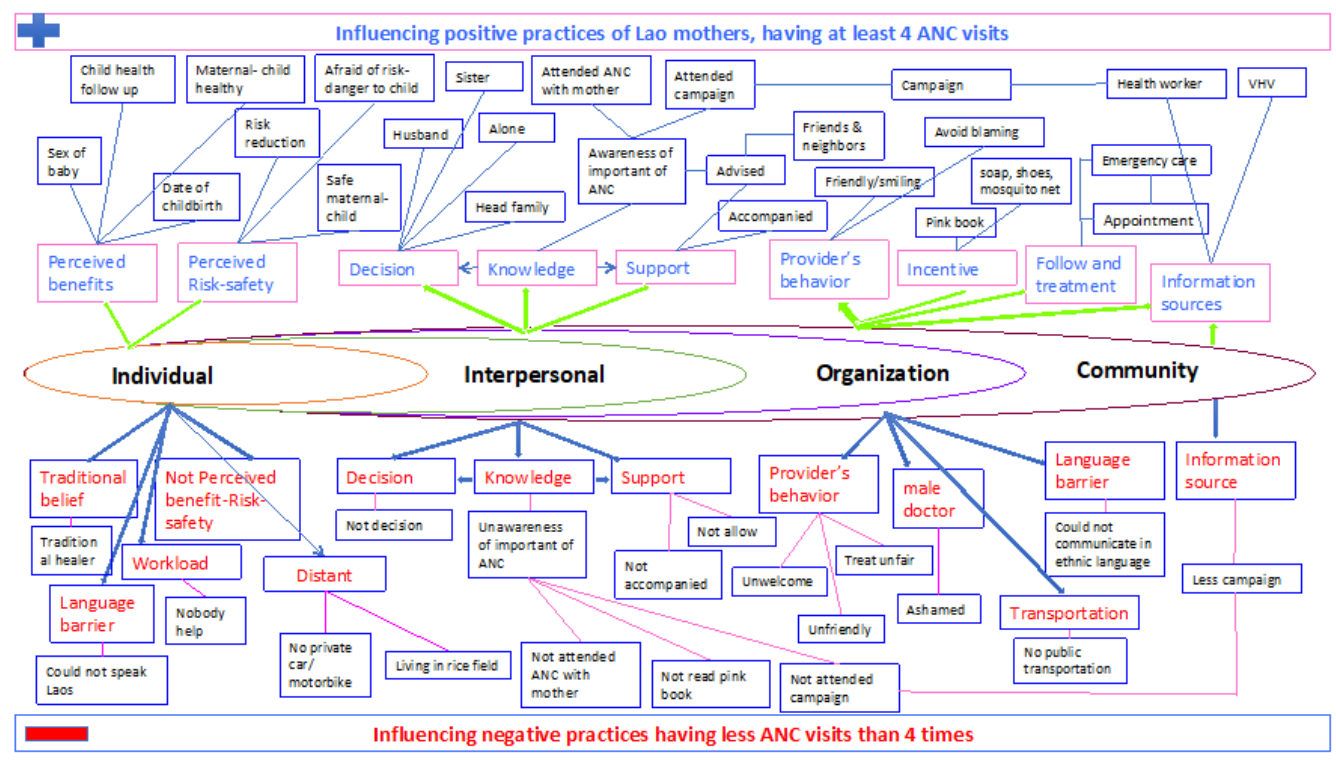

Figure 2. Comparison of Influencing Factors on Positive and Negative Practices of Lao Mothers. 


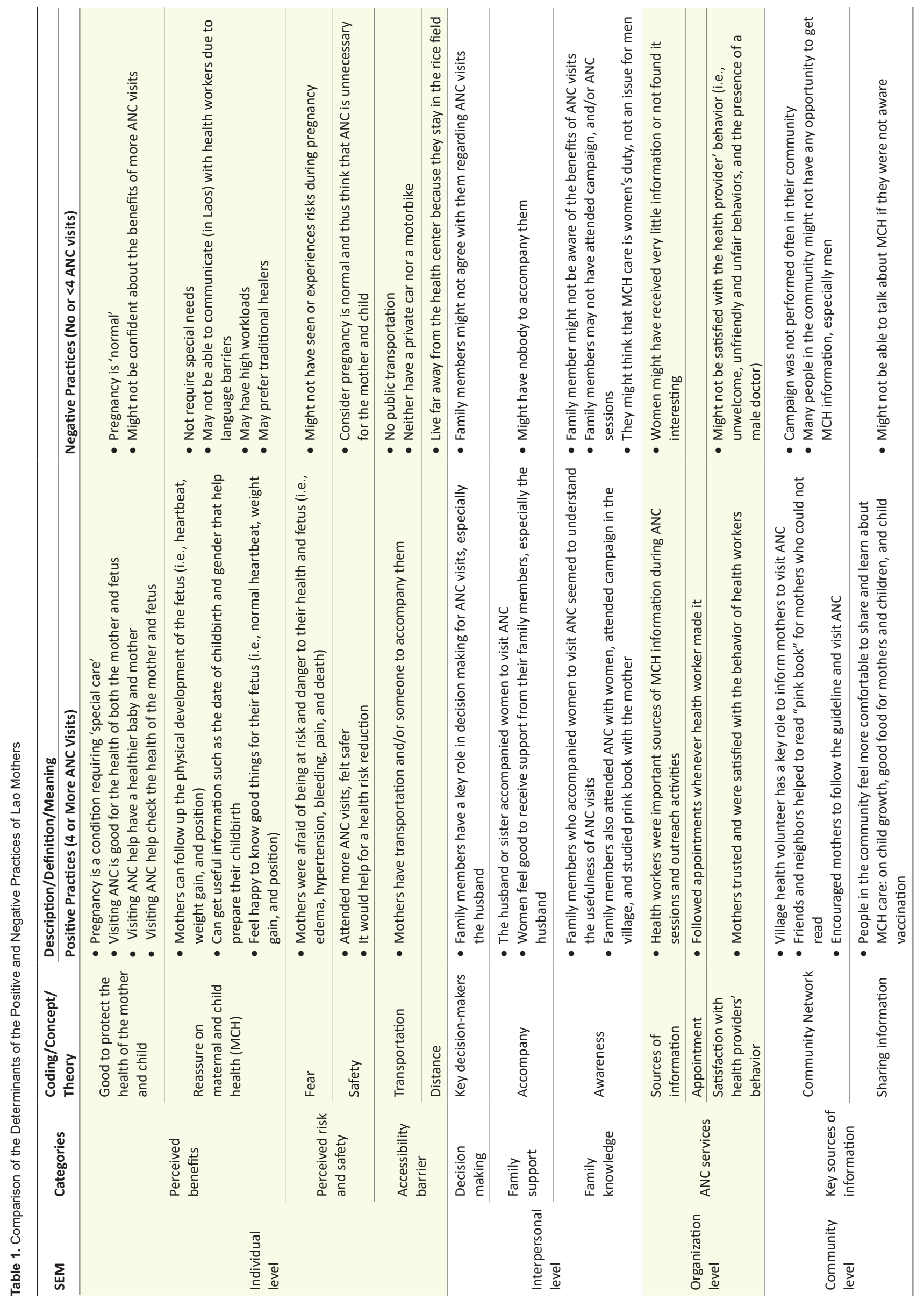


"I did not go to the forest and the rice field during pregnancy. My husband allowed me to stay at home because he heard that from health workers when attending ANC with me, so I could take more rest than before." (Participant No. 3)

More ANC visits were identified as one of the most important items for special care. All women mentioned that the reason for visiting ANC more frequently is to take care of both the baby and mother's health.

"I think that every pregnant woman needs special care through ANC visits because there you can have specific care for the mother and child's health." (Participant No. 10)

All positive deviance mothers also indicated that visiting ANC is very good for protecting themselves and their fetuses because health workers could check the health of both the mother and baby. Most women reported that they received useful information during $\mathrm{ANC}$ and perceived that ANC visits would help them in their pregnancy. These mothers were particularly interested in following the development of their fetuses, which brought them a sense of happiness.

"It was very useful for my childbirth preparedness because the health worker could tell about the date of my childbirth and the baby's gender." (Participant No. 7)

"I would like to follow up the physical development (i.e., heartbeat, weight gain, and position) of my fetus and I am eager to know from the health worker about my health and that of my fetus. When the doctor said that both the mother and fetus are healthy, I was very happy." (Participant No. 10)

Additionally, some mothers mentioned that they were afraid of risks during pregnancy and danger to their babies if they did not follow up health workers thus more ANC visits would help reduce any risk by frequent monitoring.

"My previous pregnancy had risks like hypertension and edema, so I'm afraid of any danger to my baby. Villagers and traditional birth attendants could not help, therefore, I went to see the health worker at ANC more often." (Participant No. 4)

Our participants also reflected upon reasons for other mothers who did not follow ANC. The positive deviance mothers thought that others might not be motivated if they were not confident about the benefits. Further, if they reasoned that pregnancy is 'normal' and requires no special needs, they may prefer to see traditional healers, or may be unable to communicate (in Lao language) with health workers or may have a high workload.

"Some mothers in my village believe that being pregnant is normal and there is no need for special care from health workers, so a traditional healer is the first option to visit if something does happen." (Participant No. 1)

"Many women in my village could not speak the Lao language, so if nobody could accompany them to communicate with health workers, they might not visit ANC." (Participant No. 3)

Another barrier to ANC attendance was that many mothers lived in rice fields and had no private car or motorbike, making it difficult for them to visit the health center for ANC. The positive deviance women always had a means of transport at their disposal.

\section{Interpersonal Level}

Family members played a key role in decision-making and support for mothers to make more ANC visits when they were aware of the importance of ANC. All women reported that family members were the key to their decision to visit ANC and to deliver at a health facility. A few women mentioned that they could go for ANC alone after their husbands showed their agreements, but many women were accompanied by their husbands or sisters for ANC. Most women also indicated that their husbands agreed with or advised their ANC visits, and those husbands were likely to understand how important ANC visits were for $\mathrm{MCH}$.

"I do agree that family members, especially the head of the family, is a very important person in this matter. Fortunately, my husband quite understands that I should have ANC, he said that health workers can help check my health and that of the baby. He accompanied me." (Participant No. 2)

A few participants reported that friends and neighbors were a very useful source of information and support. For example, three mothers with no reading literacy were helped by a neighbor to go through the ANC information booklet (pink book).

"I asked one of my neighbors to read the pink book when I wanted to know more about child development and vaccination because I cannot read nor could my family members read for me." (Participant No. 19)

In these communities, sharing good experiences and joy with other people are common practices. Most mothers were proud of sharing their positive experiences of care.

"Talking with friends about the good experience of my ANC visit was more comfortable and enjoyable than talking with other people. I could also advise my friends to frequently visit ANC based on my experiences" (Participant No. 2)

In contrast, participants explained that mothers who followed no ANC or had fewer visits might not receive such positive support from their family members, friends, and neighbors as they did. Perhaps family members might not allow them to go if they were unaware of the importance of ANC. They mentioned that not all husbands or family members were interested in attending ANC visits with their wives or attending campaigns in the community.

"I think that not all pregnant women are so lucky to get good support from their family, especially their husbands. I found that some of my neighbors were not only restricted to get ANC but also did not attend any village health campaign, or had any help for work, as my husband did for me." (Participant No. 8)

\section{Organization Level}

The ANC service was noted as an important source 
of information and care for $\mathrm{MCH}$. All participants mentioned that they wanted more information about their baby's health from health workers, and professionals helped them to follow up the health of the baby. Most interviewed mothers reported that they also received information about ANC benefits from health workers during immunization campaigns in the village. Many women declared that following the appointments made by health workers was a common practice during their pregnancy. These mothers trusted and were satisfied with the behavior of their health workers and indicated that they were friendly.

"I have never been blamed by health workers because I have never missed an appointment. In addition, I have done whatever the doctor told me because I think that the doctor's advice is good for my health and that of my fetus." (Participant No. 13)

"When I visited ANC, I felt more comfortable with the doctor who was kind and talked well with me because of our kinship. I was asked to come more often if I was in pain." (Participant No. 15)

In some cases, incentives provided by health workers were interesting and useful to the mothers. For example, they told us that health workers provided a soap, a pair of shoes, and a pink book for us to take home. All participants pointed out that the pink book was very useful to bring home and share with their family members because -it contains a great deal of information about child growth, immunization, and nutrition in addition to recording pregnancy status.

"I got a pink book when I went for my first ANC visit. It was very useful to read more at home because the health worker did not tell me very much about my health and the baby, but I could find more information in the pink book, especially about child vaccination." (Participant No. 10)

The mothers thought that other mothers that did not attend or hardly attended ANC might have had a negative experience when going for ANC or other health care services, which would lead them to avoid ANC. For example, pregnant women might experience feeling unwelcome or encounter unfriendly and unfair health workers during ANC sessions.

"When I advised my friend to visit ANC, she told me that she was afraid of the doctor who used to blame her when she forgot to take her pink record book with her when going for ANC." (Participant No. 15)

The lack of public transportation in their village, making it difficult for some pregnant mothers to visit the health center for ANC, especially those mothers who lived in rice fields and had no private car or motorbike.

\section{Community Level}

The community is also an important source of information, a key source for our positive deviance mothers, which encourages them to seek ANC. Many mothers mentioned that village health volunteers had a role in informing mothers about visiting ANC. These participants indicated that community networks and support stimulated them to attend ANC. Moreover, the pink book provided by health workers during ANC had a catalytic effect as many pregnant women could not read and asked friends and neighbors to read it for them. In other words, the shared interpretation of the book led to increased motivation in the community to follow the guidelines. More precisely, it provided a good opportunity for community members to learn more about $\mathrm{MCH}$ care, which thus supported mothers to visit ANC.

"Although I could not read my pink book, I shared it with my friends and neighbors. They became more interested in the child's growth and healthy food for the mother and child." (Participant No. 9)

The health education campaigns were a good source of information for pregnant women and their families. However, not everyone in the community had the opportunity to hear that information, partly because campaigns were not organized as often as needed in the village. Additionally, some people in the village might not be interested in the campaign, especially men, who might think that attending a campaign on $\mathrm{MCH}$ is not their role, but the duty of women.

"Campaigns on MCH were organized in my village for the last three years and not many men attended this important event because they believed that the campaign was not relevant for men but was useful for women." (Participant No. 5).

\section{Discussion}

In contrast to previous studies in Laos, this study focused on rural mothers with good ANC practices and the factors that motivated and influenced these women. It was expected that understanding the determinants of this positive deviant behavior at different levels would inform potential intervention strategies to achieve optimal ANC utilization.

\section{Individual Level}

At the individual level, motivation for utilizing ANC came from positive perceptions of the benefits of ANC and risk reductions. In some cases, women were even more motivated because it was their first pregnancy and they wanted to reassurance that all was going well or since they had faced difficulties in a previous pregnancy and wanted to do all possible to make sure this pregnancy would go well. In general, women in our study received what they called 'special care' during pregnancy because they did not regard pregnancy as 'normal'. They had all attempted to acquire information on $\mathrm{MCH}$. These findings support those of previous studies in other countries, indicating that having good $\mathrm{MCH}$ knowledge, being concerned about their health, and perceiving ANC as useful were significantly associated with optimum ANC utilization..$^{10,12,13,15,16}$ A report from Ethiopia demonstrated 
that mothers who had a positive perception toward ANC visits were more likely to achieve good care during pregnancy. ${ }^{23,24}$ In contrast, mothers who did not perceive the risks of pregnancy and the benefits of optimal ANC visits would have less or no ANC utilization. 24,30,31

Positive deviant mothers did not face certain barriers that others might, including the lack of transport to the clinic or barriers such as distance or language. In addition, the lack of transportation is considered as one of the barriers to using ANC for many mothers in rural areas that were identified in other studies. ${ }^{8,13,16}$

\section{Interpersonal Level}

The women in our study reported that the support of family members, especially husbands, was one of the important factors to allocate time and money to follow ANC care. Their families felt that pregnancy required 'special care' and included attending ANC and following the instructions of the health care providers. A previous study also found that husbands (and mothers-in-law) played strong roles in influencing optimal ANC visits because they are powerful in family decision-making for health care. ${ }^{25}$ Thus, interventions should try to attract family members for involvement in $\mathrm{MCH}$ activities as a crucial strategy and a possible target to improve ANC utilization.

Information and support from friends and neighbors were also important. For example, friends and neighbors assisted mothers with no writing and reading literacy, especially to read their pink books for ANC visits. A previous study in England also demonstrated that peer support (not family members) has a very important role in monitoring and supporting pregnant women, especially vulnerable and newly pregnant women. ${ }^{27}$

Studies in other countries concluded that high family incomes, good occupations, and financial support from husbands were significantly associated with four or more ANC visits. ${ }^{6,711,12,16,26}$ In our samples, family and husbands' incomes and occupations of all women were all at a rather low level, thus reflecting the importance of the context in priority for different influencing factors.

\section{Organization Level}

ANC is not only to support risk analysis and management but also to track the joyful experience of a growing fetus during the pregnancy. One important item in good quality ANC services is to provide useful information about the progress of fetal growth and to monitor the health of both the mother and the baby. This was a motivating factor for our mothers, which is in line with the findings of other studies in Ethiopia, ${ }^{3}$ as well as our recent study. ${ }^{29-31}$ Unfortunately, the quality of ANC provision in Laos remains poor, especially, as previously described, communication skills and information provision. ${ }^{27-29}$

Positive deviant mothers were satisfied with the received care and all used the pink book they received during ANC, but they were aware that other mothers may not have a similar perspective. They further suggested that mothers' negative experiences because of the negative behavior and attitudes of health providers might be a reason for mothers not to achieve optimal ANC visits, which is consistent with the results of our previous studies. ${ }^{27-29}$ Increasing women's satisfaction with the quality of ANC provision would also be important for increasing ANC visits. Therefore, the health care system needs to be responsive to clients' satisfaction with the quality of ANC services, ${ }^{27-29,32-35}$ which could help women who have not achieved optimal ANC visits. On the other hand, emphasizing the improvement of making and keeping appointments between health workers and pregnant women was also reported to be an important factor regarding increasing optimal ANC visits. The health centers in these rural villages also offered incentives, which motivated women to attend ANC, as was noted in Nepal. ${ }^{36}$

In brief, improving the quality of ANC provision, particularly the capacity to provide positive and useful information, agreement on the next appointments, and the appropriate behavior and attitude of health workers during communication could make pregnancy a special and joyful process for pregnant women and family members.

\section{Community Level}

The WHO recommends interventions at the community level to support pregnant women. ${ }^{4}$ A meta-analysis of intervention studies in low- and middle-income countries demonstrated that a single intervention, especially community campaigns on $\mathrm{MCH}$ could increase coverage to four or more ANC utilizations. ${ }^{24}$ In our study, community campaigns were also mentioned as a good source of information for community members. Unfortunately, they did not occur regularly and did not always involve as many people as needed. Moreover, they did not involve the positive role models of women who did attend ANC or men or other family members, even though it is known that their role is important. Therefore, conducting interventions using effective information, education and communication (IEC) with new approaches for campaigns could lead to improved ANC uptake. Additionally, new IEC approaches are needed to increase the interest and awareness of $\mathrm{MCH}$ care among all villagers in order to motivate more women to seek ANC.

Community members could also play a role as a source of information in $\mathrm{MCH}$ care. In this study, it was found that positive mothers in the community were likely to share their experiences and information among their friends and neighbors, and there seemed to be a willingness to assist mothers who could not write and read, especially to read their pink record books for ANC visits. Village health volunteers also greatly contributed to convey key messages on $\mathrm{MCH}$ in the community and to encourage mothers to seek ANC. Community interventions including village 
health volunteers could form an effective channel to reach mothers and increase their use of ANC. Accordingly, it would be good to involve mothers with positive deviant behaviors in providing motivating information to other women in this regard.

This study had some limitations. First, we did not know whether the mothers mainly came for ANC visits at the end of their pregnancy, or really had gone regularly throughout because the questions focused on the number of visits. In addition, this qualitative study on women with positive deviant behaviors was only carried out in one province in Southern Laos thus it may not be generalizable to the whole country. However, the participants may represent a wider range of women sharing the rural location and other socio-economic characteristics and making up the majority of women in Laos.

\section{Conclusions}

Taking 'special care' of self during pregnancy was a common feature among Lao mothers with positive deviant behaviors with respect to ANC attendance. They also received support from their families particularly their husbands, friends, and neighbors, and were encouraged by health services. The results suggested that the improvement of ANC coverage could be achieved by health services through paying attention to both families and communities. The services need to improve the quality of the provided information and applied methods so that more mothers become aware that pregnancy requires 'special care' and thus appreciate the value of ANC services. This would require strengthening the capacity of health care workers to provide better services and investing in community information sessions aiming at women, as well as husbands and other family members. Finally, involving mothers who did utilize ANC as recommended in community activities to encourage more mothers in this regard is suggested as well.

\section{Authors' Contribution}

All authors equally contributed to this work.

\section{Conflict of Interests}

Authors declare that they have no conflict of interests.

\section{Ethical Issues}

The ethics approval for this study, as part of a large project on the "situation analysis of $\mathrm{MCH}$ care in Lao people's democratic republic (PDR)", was obtained from the Ethical Research Committee of University of Health Sciences, the Ministry of Health, Lao PDR (No 0681, issued on 09 March 2017).

Before starting the interview, the interviewers explained the aim of the study and the general topics for discussion. Then, participants were assured of data confidentiality and could withdraw at any moment without giving a reason. Written consent was obtained before interview initiation, and women with no reading and writing literacy provided fingerprints.

\section{Financial Support}

The research was conducted under the support of the European Union funded LEARN Project (Number: DCI/ SANTI/2014/342-306) through the Medical Committee Netherlands-Vietnam (MCNV) in Lao PDR.

\section{References}

1. Session S, Care PA. Antenatal Care Module: 2. Promoting Antenatal Care. 2019. https://www. open.edu/openlearncreate/mod/oucontent/view. php?id=32\&printable $=1$.

2. Maternal and Reproductive Health Division. National Guidelines for Antenatal Care for Service Providers. http://themimu.info/sites/themimu.info/files/documents/ Ref_Doc_National_Guidelines_for_Antenatal_Care_for_ Service_Providers_May2018.pdf. Published May 2018.

3. World Health Organization (WHO). WHO Recommendations on Antenatal Care for A Positive Pregnancy Experience. Geneva: WHO; 2016:152.

4. Muchie KF. Quality of antenatal care services and completion of four or more antenatal care visits in Ethiopia: a finding based on a demographic and health survey. BMC Pregnancy Childbirth. 2017;17(1):300. doi:10.1186/s12884017-1488-0

5. Tekelab T, Chojenta C, Smith R, Loxton D. Factors affecting utilization of antenatal care in Ethiopia: a systematic review and meta-analysis. PLoS One. 2019;14(4):e0214848. doi:10.1371/journal.pone.0214848

6. Adewuyi EO, Auta A, Khanal V, et al. Prevalence and factors associated with underutilization of antenatal care services in Nigeria: a comparative study of rural and urban residences based on the 2013 Nigeria demographic and health survey. PLoS One. 2018;13(5):e0197324. doi:10.1371/journal. pone.0197324

7. Ayalew TW, Nigatu AM. Focused antenatal care utilization and associated factors in Debre Tabor Town, northwest Ethiopia, 2017. BMC Res Notes. 2018;11(1):819. doi:10.1186/s13104-018-3928-y

8. Ali N, Sultana M, Sheikh $\mathrm{N}$, et al. Predictors of optimal antenatal care service utilization among adolescents and adult women in Bangladesh. Health Serv Res Manag Epidemiol. 2018;5:2333392818781729. doi:10.1177/2333392818781729

9. Hajizadeh S, Ramezani Tehrani F, Simbar M, Farzadfar F. Factors influencing the use of prenatal care: a systematic review. J Midwifery Reproductive Health. 2016;4(1):544557. doi:10.22038/jmrh.2016.6431

10. Noh JW, Kim YM, Lee LJ, et al. Factors associated with the use of antenatal care in Sindh province, Pakistan: a population-based study. PLoS One. 2019;14(4):e0213987. doi:10.1371/journal.pone.0213987

11. Ha BT, Tac PV, Duc DM, Duong DT, Thi le M. Factors associated with four or more antenatal care services among pregnant women: a cross-sectional survey in eight South Central Coast provinces of Vietnam. Int J Womens Health. 2015;7:699-706. doi:10.2147/ijwh.s87276

12. Sychareun V, Somphet V, Chaleunvong K, et al. Perceptions and understandings of pregnancy, antenatal care and postpartum care among rural Lao women and their families. 
BMC Pregnancy Childbirth. 2016;16(1):245. doi:10.1186/ s12884-016-1031-8

13. Phathammavong O, Ali M, Souksavat S, Chounramany K, Kuroiwa C. Antenatal care among ethnic populations in Louang Namtha province, Lao PDR. Southeast Asian J Trop Med Public Health. 2010;41(3):705-716.

14. Manithip C, Sihavong A, Edin K, Wahlstrom R, Wessel H. Factors associated with antenatal care utilization among rural women in Lao People's Democratic Republic. Matern Child Health J. 2011;15(8):1356-1362. doi:10.1007/s10995010-0671-y

15. Ye Y, Yoshida Y, Harun-Or-Rashid M, Sakamoto J. Factors affecting the utilization of antenatal care services among women in Kham District, Xiengkhouang province, Lao PDR. Nagoya J Med Sci. 2010;72(1-2):23-33.

16. Sallis JF, Owen N, Fisher EB. Ecological models of health behavior. In: Glanz K, Rimer BK, Viswanath K, eds. Health Behavior and Health Education: Theory, Research, and Practice. San Francisco, CA: Jossey-Bass; 2008:465-485.

17. Rosenstock IM, Strecher VJ, Becker MH. Social learning theory and the health belief model. Health Educ Q. 1988;15(2):175-183. doi:10.1177/109019818801500203

18. Jones CL, Jensen JD, Scherr CL, Brown NR, Christy K, Weaver J. The health belief model as an explanatory framework in communication research: exploring parallel, serial, and moderated mediation. Health Commun. 2015;30(6):566-576. doi:10.1080/10410236.2013.873363

19. Carpenter CJ. A meta-analysis of the effectiveness of health belief model variables in predicting behavior. Health Commun. 2010;25(8):661-669. doi:10.1080/10410236.201 0.521906

20. Poux S. Social Ecological Model Offers New Approach to Public Health. The Borgen Project; 2017.

21. LaMorte WW. Behavioral Change Models, the Health Belief Model. Boston University, School of Public Health. last modified September, 2019.

22. Ahrari M, Kuttab A, Khamis S, et al. Factors associated with successful pregnancy outcomes in upper Egypt: a positive deviance inquiry. Food Nutr Bull. 2002;23(1):8388. doi:10.1177/156482650202300111

23. Mbuagbaw L, Medley N, Darzi AJ, Richardson M, Habiba Garga K, Ongolo-Zogo P. Health system and community level interventions for improving antenatal care coverage and health outcomes. Cochrane Database Syst Rev. 2015(12):CD010994. doi:10.1002/14651858.CD010994. pub2

24. Edie GE, Obinchemti TE, Tamufor EN, Njie MM, Njamen TN, Achidi EA. Perceptions of antenatal care services by pregnant women attending government health centres in the Buea Health District, Cameroon: a cross sectional study. Pan Afr Med J. 2015;21:45. doi:10.11604/ pamj.2015.21.45.4858

25. Waller A, Bryant J, Cameron E, Galal M, Quay J, SansonFisher R. Women's perceptions of antenatal care: are we following guideline recommended care? BMC Pregnancy Childbirth. 2016;16(1):191. doi:10.1186/s12884-0160984-y
26. Upadhyay P, Liabsuetrakul T, Shrestha AB, Pradhan N. Influence of family members on utilization of maternal health care services among teen and adult pregnant women in Kathmandu, Nepal: a cross sectional study. Reprod Health. 2014;11:92. doi:10.1186/1742-4755-11-92

27. McLeish J, Redshaw M. Peer support during pregnancy and early parenthood: a qualitative study of models and perceptions. BMC Pregnancy Childbirth. 2015;15:257. doi:10.1186/s12884-015-0685-y

28. Wolderufael TS. Factors Influencing Antenatal Care Service Utilization Among Pregnant Women in Pastoralist Community in Menit-Shasha District, Ethiopia. Int J Med Res Health Sci. 2018;7(5):143-156.

29. Phommachanh S, Essink DR, Jansen M, Broerse JEW, Wright P, Mayxay M. Improvement of Quality of Antenatal Care (ANC) Service Provision at the Public Health Facilities in Lao PDR: Perspective and Experiences of Supply and Demand Sides. BMC Pregnancy Childbirth. 2019;19(1):255. doi:10.1186/s12884-019-2345-0

30. Phommachanh S, Essink DR, Wright EP, Broerse JEW, Mayxay M. Do health care providers give sufficient information and good counseling during ante-natal care in Lao PDR?: an observational study. BMC Health Serv Res. 2019;19(1):449. doi:10.1186/s12913-019-4258-z

31. Phommachanh S, Essink DR, Wright EP, Broerse JEW, Mayxay M. Overt versus covert observations on health care providers' care and communication during antenatal care visits in Lao PDR. J Glob Health Sci. 2019;1(1):e11. doi:10.35500/jghs.2019.1.e11

32. Tesfaye T, Mekonnen H, Negesa L. Maternal Antenatal Care Service Satisfaction and Factors Associated with Rural Health Centers, Bursa District, Sidama Zone, Southern Ethiopia: A Crosssectional Study. J Women's Health Care. 2017;6(2):363. doi:10.4172/2167-0420.1000363

33. Galle A, Van Parys AS, Roelens K, Keygnaert I. Expectations and satisfaction with antenatal care among pregnant women with a focus on vulnerable groups: a descriptive study in Ghent. BMC Womens Health. 2015;15:112. doi:10.1186/ s12905-015-0266-2

34. Chemir F, Alemseged F, Workneh D. Satisfaction with focused antenatal care service and associated factors among pregnant women attending focused antenatal care at health centers in Jimma town, Jimma zone, South West Ethiopia; a facility based cross-sectional study triangulated with qualitative study. BMC Res Notes. 2014;7:164. doi:10.1186/1756-0500-7-164

35. Dauletyarova MA, Semenova YM, Kaylubaeva G, et al. Are Kazakhstani women satisfied with antenatal care? implementing the WHO tool to assess the quality of antenatal services. Int J Environ Res Public Health. 2018;15(2). doi:10.3390/ijerph15020325

36. Bhatt H, Tiwari S, Ensor T, Ghimire DR, Gavidia T. Contribution of Nepal's free delivery care policies in improving utilisation of maternal health services. Int $\mathrm{J}$ Health Policy Manag. 2018;7(7):645-655. doi:10.15171/ ijhpm.2018.01 original work is properly cited. 